
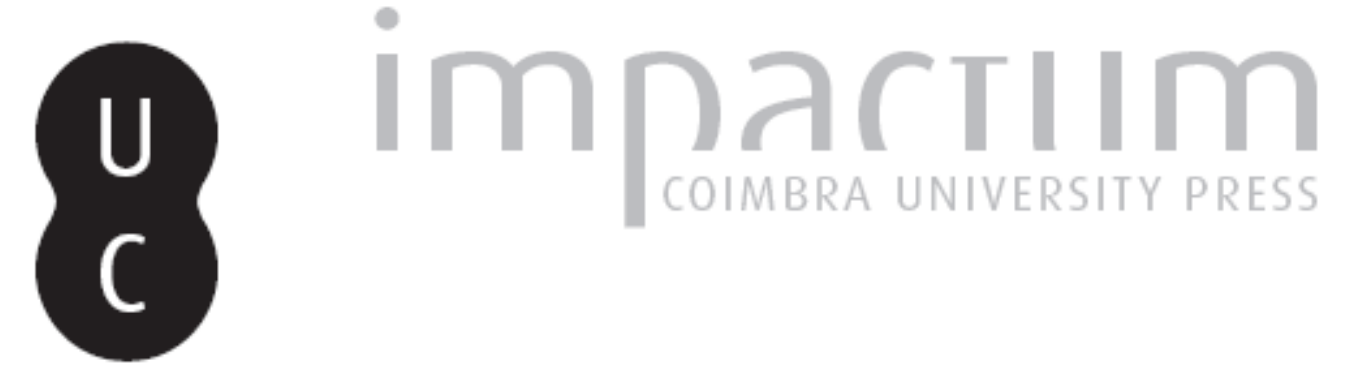

La primera madurez de las ciencias históricas en España: 1900-1936

Autor(es): $\quad$ Ladero Quesada, Miguel Ángel Publicado por: Faculdade de Letras da Universidade de Coimbra, Instituto de História

URL persistente:

URI:http://hdl.handle.net/10316.2/27902

DOI:

DOI:http://dx.doi.org/10.14195/0870-4147_42_7

Accessed : $\quad$ 26-Apr-2023 00:11:27

A navegação consulta e descarregamento dos títulos inseridos nas Bibliotecas Digitais UC Digitalis, UC Pombalina e UC Impactum, pressupõem a aceitação plena e sem reservas dos Termos e Condições de Uso destas Bibliotecas Digitais, disponíveis em https://digitalis.uc.pt/pt-pt/termos.

Conforme exposto nos referidos Termos e Condições de Uso, o descarregamento de títulos de acesso restrito requer uma licença válida de autorização devendo o utilizador aceder ao(s) documento(s) a partir de um endereço de IP da instituição detentora da supramencionada licença.

Ao utilizador é apenas permitido o descarregamento para uso pessoal, pelo que o emprego do(s) título(s) descarregado(s) para outro fim, designadamente comercial, carece de autorização do respetivo autor ou editor da obra.

Na medida em que todas as obras da UC Digitalis se encontram protegidas pelo Código do Direito de Autor e Direitos Conexos e demais legislação aplicável, toda a cópia, parcial ou total, deste documento, nos casos em que é legalmente admitida, deverá conter ou fazer-se acompanhar por este aviso.

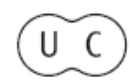





\title{
La primera madurez de las ciencias históricas en España. 1900-1936
}

\author{
Miguel Ángel Ladero Quesada \\ Universidad Complutense \\ Departamento de Historia Medieval \\ mladero@ghis.ucm.es
}

Resumo:

Progresos en la institucionalización de los estudios históricos en España durante el primer tercio del siglo XX y novedades que introducen con respecto a la situación en la segunda mitad del XIX. Reforma universitaria, planes de estudio, edición de síntesis y libros de metodología y formación de núcleos de investigación. Organización y desarrollo del Centro de Estudios Históricos. Continuidad de la Academia de la Historia y promoción de los estudios históricos regionales. Aportaciones de los hispanistas franceses y de otros países. Mención a los historiadores principales de aquel tiempo, sus temas y métodos de investigación y explicación de la historia de España.

Palavras chave:

España; Historiografía; 1900-1936.
Abstract:

The following topics will be addressed: advances in the institutionalization of historical studies in Spain during the first third of the $20^{\text {th }}$ century and new aspects introduced in comparison with the second half of the $19^{\text {th }}$ century; university reforms, curricula, publishing of reference books and books on methodology, constitution of research nuclei; organization and development of the Centro de Estudos Históricos (Centre for Historical Studies); permanence of the Academy of History and promotion of historical regional studies; the contribution of French hispanists (and from other countries); most important historians of the period, the subjects they dealt with, their methods for researching and interpreting the history of Spain.

Keywords:

Spain; Historiography; 1900-1936. 


\section{Preámbulo}

Los "comienzos de la profesionalización" de los historiadores se observan desde mediados del siglo XIX, dentro de las corrientes de "nueva sensibilidad" historicista de la época y mediante los cauces institucionales nuevos o vueltos a abrir ${ }^{1}$.

Por una parte, se reorganizó la Real Academia de la Historia, junto con las otras Academias, en febrero de 1847, estableciendo su vínculo con el gobierno a través del nuevo Ministerio de Fomento (1851). La Academia desplegó una actividad intensa y variada durante los siguientes cincuenta años en los ámbitos de rescate y conservación documental, en especial de los fondos monásticos desamortizados, de la edición de colecciones documentales y de otras fuentes, de la descripción del patrimonio arqueológico y artístico, y del amparo a la elaboración de grandes síntesis sobre la Historia de España como la que emprendió Modesto Lafuente Zamalloa a título individual, a mediados del siglo, o la que se proyectó en sus últimos decenios bajo la dirección de Antonio Cánovas del Castillo, que fue director de la Academia entre 1882 y 1897.

Además, la Academia promovió la formación de personal especializado en erudición histórica y archivística consiguiendo del gobierno la puesta en marcha de la Escuela Superior de Diplomática en octubre de 1856 y la creación del Cuerpo Facultativo de Archiveros, Bibliotecarios y Anticuarios en 1858. El siguiente paso fue la fundación del Archivo Histórico Nacional en 1866. La Academia cedió local, instalaciones y mobiliario alojando al Archivo hasta que en 1896 se instaló en el Palacio de la Biblioteca y Museos Nacionales. Otra manifestación sobresaliente de la madurez que se estaba alcanzando fue el nacimiento de las dos revistas históricas más antiguas de nuestro país: la Revista de Archivos, Bibliotecas y Museos y el Boletín de la Real Academia de la Historia, desde 1871 y 1876 respectivamente ${ }^{2}$.

1 Un esbozo general sobre teoría y método del conocimiento histórico del siglo XIX en Gonzalo Pasamar Alzuría e Ignacio Peiró Martín, "Los inicios de la profesionalización historiográfica en España (regeneracionismo y positivismo)", en Historiografía y práctica social en España, Zaragoza, 1987. Tomo de este libro las citas entrecomilladas en el párrafo.

2 Una exposición más amplia en Miguel Ángel Ladero Quesada, "El papel de la Real Academia de la Historia”, en La historia medieval hoy: percepción académica y percepción social. XXXV Semana de Estudios Medievales de Estella, Pamplona, Gobierno de Navarra, 2009, pp. 171-191. Bibliografía de referencia principal: Ignacio Peiró Martín, Los guardianes de la historia. La historiografía académica de la restauración, Zaragoza, Institución Fernando el Católico, 2006. Benoit Pellistrandi, Un discours national? . La Real Academia de la Historia entre science et politique (1847-1897), Madrid, Casa de Velázquez, 2004. Ignacio Peiró Martín, Gonzalo Pasamar Alzuria, La Escuela Superior de Diplomática (los archiveros en la historiografía 
$\mathrm{Al}$ acoger la Escuela de Diplomática, donde se formaron casi todos los archiveros, el fondo de documentos desamortizados y el mismo Archivo Histórico Nacional, la Academia creó una relación estrecha con el mundo profesional de los archiveros, y así se pudo aplicar a la conservación y clasificación documental y a la investigación los principios de crítica y método propios del positivismo historiográfico en una época de escasísimo desarrollo de los estudios históricos en la Universidad, concebida entonces, además, como institución de enseñanza mucho más que de investigación. En la intersección de aquellas realidades (bibliotecas y archivos, universidad, academias) floreció desde 1875 la personalidad excepcional de Marcelino Menéndez Pelayo ${ }^{3}$.

En aquel momento, hacía ya tres decenios que la legislación sobre enseñanza promulgada después de la revolución liberal había abierto las puertas a la enseñanza de la Historia en la Universidad, por primera vez, en el seno de la Facultad de Filosofía y Letras, heredera de la antigua Facultad de Artes. La ley de instrucción pública del ministro Claudio Moyano (9 septiembre 1857), recogía las iniciativas de anteriores leyes, desde 1845, e incluía en el plan de estudios asignaturas de "Historia Universal" e "Historia crítica de España", dotando las cátedras correspondientes, además de fijar las materias que enseñaba la Escuela de Diplomática ${ }^{4}$, que permanecía al margen de la organización universitaria aunque ya en 1873 hubo un primer proyecto para integrarla en una Facultad de Letras, diferenciada de la de Filosofía, de la que habrían dependido también orgánicamente el Archivo Histórico Nacional y el Museo Arqueológico Nacional, de modo que proporcionaran conexión entre enseñanza e investigación, estudios y salidas profesionales. Fallido este intento,

española contemporánea), Madrid, Anabad, $1996 ; 150^{\circ}$ aniversario de la fundación de la Escuela Superior de Diplomática. Reglamento y programas, Madrid, Real Academia de la Historia, 2007 (en especial el capítulo escrito por Martín Almagro Gorbea: "La Real Academia de la Historia y la Escuela Superior de Diplomática”, pp. 13-32). Es de interés conocer los planteamientos historiográficos de uno de los principales promotores, Tomás Muñoz y Romero, Sobre la necesidad de fomentar el estudio de la Edad Media, Madrid, 1860 (discurso de ingreso en la Real Academia de la Historia). Miguel Ángel Álvarez Ramos, Cristina Álvarez Millán, Los viajes literarios de Pascual de Gayangos (1850-1857) y el origen de la archivística española moderna, Madrid, CSIC, 2007. Vicente Vignau y Ballester, El Archivo Histórico Nacional, Madrid, 1898.

3 Breve introducción en Vicente Palacio Atard, "Marcelino Menéndez Pelayo. El Polígrafo", Catedráticos en la Academia, Académicos en la Universidad, Madrid, 1993, pp. 247-262. José Alberto Vallejo del Campo, Menéndez Pelayo, historiador. Su formación y su concepción de la disciplina, Santander, 1998. De entre la bibliografía clásica sobre el autor, Pedro Laín Entralgo, Menéndez Pelayo. Historia de sus problemas intelectuales, Madrid, 1944.

4 Eran éstas: Paleografía general, Paleografía crítica, Latín de los tiempos medios, Romance, Lemosín y gallego, Arqueología y numismática, Historia de España en los siglos medios, Bibliografía, Clasificación y arreglo de bibliotecas y archivos. 
apenas hubo cambios hasta la reforma de 1900 pero en los dos últimos decenios del siglo XIX fueron tomando forma impulsos renovadores que demandaban potenciar la investigación de la Historia en la Universidad y mejorar tanto las asignaturas y sus contenidos como los métodos de la enseñanza, acogiendo las ideas del positivismo científico, la influencia de la nueva sociología y la del método ius-historiográfico para el desarrollo, respectivamente, de la "historia externa" o general, la "historia interna" o de la civilización y la "historia del derecho y de las instituciones".

Aquellas ideas se integraban en una corriente más amplia que buscaba reformar el sistema desde dentro, modificar la educación, la actitud de la sociedad ante la cultura y la ciencia, de modo que éstas fueran estímulos eficaces del progreso nacional. Algunos autores han denominado a este programa como "regeneracionismo de cátedra", relacionándolo, en general, con la situación social y política de España entre la restauración de 1875 y el desastre colonial de 1898: se suelen adscribir a esta tendencia nombres tan destacados, y diversos en su significación profesional a finales del siglo XIX, como los de Joaquín Costa $^{6}$, Esteban Pérez Pujol,_Eduardo de Hinojosa ${ }^{7}$, Rafael Altamira ${ }^{8}$, Adolfo Posada, Julián Ribera o Eduardo Ibarra.

5 Entre los proyectos destaca el expuesto por Rafael Altamira en su extraordinario libro La enseñanza de la Historia, Madrid, 1891 (1895, $2^{\mathrm{a}}$ ed. ampliada; 1997, $3^{\mathrm{a}}$ ed.), pp. 327-348: "X. Organización de la enseñanza superior de la Historia en España". Un resumen de la legislación universitaria sobre la enseñanza de la Historia desde 1845 hasta 1913 en José Deleito y Piñuela, La enseñanza de la Historia en la Universidad española y su reforma posible, Valencia, 1918 (nueva edición por Pedro Ruiz Torres, Discursos sobre la historia. Lecciones de apertura de curso en la Universidad de Valencia (1870-1937), Valencia, 2000.

6 George J. G. Cheyne, Joaquín Costa, el gran desconocido, Barcelona, 2011 (1 $\left.{ }^{\mathrm{a}} \mathrm{ed} .1972\right)$.

7 A señalar el carácter innovador de su Historia general del derecho español, Madrid, 1887. La reedición de su El elemento germánico en el Derecho español (Madrid, 1993) incluye una bio-bibliografía escrita por Francisco Tomás y Valiente, autor también del capítulo correspondiente a Hinojosa en la obra colectiva titulada Catedráticos en la Academia, Académicos en la Universidad, Madrid, 1993.

8 La importancia de Rafael Altamira (1866-1951) en la renovación de las ciencias históricas ha dado lugar a abundante bibliografia. Vicente Ramos, Rafael Altamira, Madrid, 1968 y Palabra y pensamiento de Rafael Altamira, Alicante, 1987. Armando Alberola, ed., Estudios sobre Rafael Altamira, Alicante, 1987. Rafael Asín Vergara et alii, Rafael Altamira (1866-1951), Alicante, 1987. J. Malagón, S.Zavala, Rafael Altamira y Crevea. El historiador y el hombre, México, 1986. Luis García de Valdeavellano, "Don Rafael de Altamira o la historia como educación", Boletín de la Real Academia de la Historia, 160 (enero-marzo 1967), 63-88. José Antonio Maravall, "La concepción de la historia de Altamira", Cuadernos Hispanoamericanos, 477-478 (1990). José María Jover Zamora, "Rafael Altamira y la Historia de la Civilización”, en Catedráticos en la Academia.... Son de interés las introducciones de Rafael Asín Vergara a algunos libros de Altamira escritos a finales del siglo XIX y comienzos del XX (La enseñanza de la Historia, 
La Institución Libre de Enseñanza tuvo una función importante en la germinación y el desarrollo de aquellas ideas y prácticas: la Institución nació en 1876 por iniciativa de Francisco Giner de los Ríos y algunos otros catedráticos excluidos de la Universidad aquel año. Giner y sus colaboradores fueron capaces de proponer un programa de reformismo pedagógico integral, inspirado en principios krausistas de filosofía liberal laica y en los modelos de cambio educativo de países europeos occidentales, en especial Francia y Alemania, a la vez que desarrollaban una actitud reformadora de las realidades de España que se fundaba en un patriotismo expresado de manera propia -se ha hablado de su "heterodoxia crónica" con respecto a los modelos políticos y eclesiásticos de su tiempo-pero evidentemente profundo y renovador en muchos aspectos que, con el paso del tiempo, alcanzarían difusión general ${ }^{9}$. La Institución propugnó un nuevo tipo de élite cultural que se consideraba responsable y abierta ante la sociedad, puesto que la educación era patrimonio de la sociedad misma, atrajo simpatías, partidarios y miembros, aunque también recelos y rechazo de otros sectores. Después del periodo germinal y de crecimiento en el último cuarto del siglo XIX, sus ideas y los hombres formados en su ámbito tuvieron gran influencia en las reformas educativas del primer tercio del siglo XX y en las instituciones encargadas de llevarlas a cabo.

\section{Las reformas en la Universidad y la enseñanza de la historia ${ }^{10}$}

El Ministerio de Instrucción Pública y Bellas Artes se desgajó del de Fomento durante el gobierno de Francisco Silvela, por real decreto de 18 de abril de 1900, ante la necesidad de incrementar los medios institucionales y los recursos que el Estado dedicaba a la atención de aquellas necesidades sociales. Una consecuencia inmediata fue el pago uniforme del sueldo de los maestros de primera enseñanza por el propio Estado, función que hasta 1902 había correspondido a los municipios: el "papel tutelar del Estado en materia

Madrid, 1997. Psicología del pueblo español, Madrid, 1998. Historia de España y de la civilización española, Barcelona, 2001).

9 La expresión es de Antonio Molero Pintado, La Institución Libre de Enseñanza: un proyecto español de renovación pedagógica, Madrid, 1985 (proporciona una visión de conjunto muy adecuada y amplia bibliografía sobre la ILE). Vicente Cacho Viu, La Institución Libre de Enseñanza. Orígenes y etapa universitaria (1860-1881), Madrid, 1962. F. Garrido, Francisco Giner de los Ríos. Creador de la Institución Libre de Enseñanza, Granada, 2001.

${ }^{10}$ Los aspectos generales de la cultura española en el primer tercio del siglo XX en Pedro Laín Entralgo, coord.., La Edad de Plata de la cultura española (1898-1936), Madrid, 1993 (Historia de España-Menéndez Pidal, XXXIX, 1 y 2). José Luis Abellán, Historia crítica del pensamiento español. V/II. La crisis contemporánea, Madrid, 1989. 
educativa" se manifestaría poco después en la extensión de la escolaridad obligatoria entre los seis y los doce años de edad. Otra reforma básica fue el nuevo plan de estudios de Bachillerato que, con pocas modificaciones, se mantuvo durante el primer tercio del siglo (R.D. 17 agosto 1901).

La reforma de la enseñanza universitaria, llevada a cabo bajo el ministro Antonio García Alix, primer titular de la cartera de Instrucción Pública, dividió la Facultad de Filosofía y Letras en tres Secciones: Filosofía, Literatura e Historia. La Escuela Superior de Diplomática desapareció y sus profesores, enseñanzas y recursos se integraron en las de la Sección de Historia de la Universidad Central. La Facultad tenía dos cursos preparatorios comunes para sus tres Secciones; la de Historia impartía a continuación otros dos cursos de licenciatura y uno de doctorado: todos ellos debían incorporar elementos de investigación, lo que incidió en la diversificación y aumento del número de asignaturas ${ }^{11}$.

Las críticas mayores, expresadas ya por Eduardo Ibarra en 1901, recogiendo sus propuestas anteriores ${ }^{12}$, y más ampliamente por Deleito y Piñuela en 1918 al proponer reformas en el cuadro de asignaturas y en los métodos de trabajo, se referían a la inexistencia o debilidad de la investigación en el marco universitario y a la falta de sintonía entre estudios realizados y posibilidades de salida profesional adecuadas a ellos. En un caso por falta de asignaturas metodológicas, seminarios y medios de investigación y, en el otro, por no haber previsto materias pedagógicas para "preparar con eficacia al futuro profesorado". Deleito, por lo demás, manifestaba también opiniones que parecen pertenecer al bagaje fijo de las lamentaciones universitarias, tales como la ausencia de una "idea clara, total, continua y sistemática" de la Historia por estudiantes que se licenciaban después de recibir unas enseñanzas compartimentadas, además,

${ }^{11}$ En los cursos comunes había sendas asignaturas de "Historia de España" e "Historia Universal". En la licenciatura se estudiaban las de "Historia antigua y media de España", "Historia universal (Edad Antigua y Media)", "Geografía política y descriptiva", "Arqueología", "Historia moderna y contemporánea de España", "Historia universal, moderna y contemporánea", "Numismática y Epigrafía". En el curso de doctorado: "Sociología", "Historia de América", "Historia de la civilización de los judíos y musulmanes", "Lenguas y literaturas neo-latinas" -ambas transferidas después a la Sección de Literatura- y se incorporaron otras cátedras en los años siguientes con asignaturas optativas tales como "Arqueología árabe" e "Historia de las Bellas Artes". También se trasladó a la Sección de Historia la enseñanza de "Paleografía", en 1913, y se impartía "Historia de las instituciones políticas y civiles de América" en los doctorados de Derecho e Historia. Los cambios legislativos en Manuel Martínez Neira, José María Puyol Montero, Carolina Rodríguez López, La universidad española 1889-1939: repertorio de legislación, Madrid, 2004.

12 Tiene gran interés precursor y como muestra del "regeneracionismo de cátedra" su obra Progreso de la ciencia histórica en el presente siglo. Discurso leído en la solemne apertura del curso académico de 1897 a 1898 en la Universidad de Zaragoza, Zaragoza, 1897. 
en cursos que no conseguían exponer las asignaturas completas, o "la crisis de la juventud universitaria", sin conciencia de su situación ni estímulos intelectuales y morales para superarla ${ }^{13}$.

Es cierto que los estudios de pedagogía se mantuvieron sin relación con la Universidad pero también alcanzaron mayor desarrollo, en gran medida bajo la inspiración del Museo Pedagógico Nacional, concebido como un "centro de recursos e innovaciones" para los maestros de enseñanza primaria. El Museo databa de 1881 y su director era Manuel Bartolomé Cossío, uno de los hombres fundamentales de la ILE. En 1909 se fundó la Escuela de Estudios Superiores del Magisterio que desapareció en 1932 al integrarse en la Facultad de Filosofía y Letras de la Universidad Central con el nombre de Sección de Pedagogía (Decreto 27 enero 1932) ${ }^{14}$. Además, desde 1914 se cursaban cuatro asignaturas de Historia en las Escuelas Normales de Magisterio, correspondientes a las cuatro "edades" clásicas: antigua, media, moderna y contemporánea. Otra iniciativa reformadora inspirada por la ILE fue la creación del Instituto-Escuela por el gobierno en 1918, como centro piloto de estudios de segunda enseñanza y de preparación de los profesores que se incorporaban a este nivel de la instrucción ${ }^{15}$.

Mientras tanto, las reformas de los planes de estudio universitarios se redujeron a retoques parciales, salvo en el curso 1931-1932, cuando se puso en marcha un plan experimental nuevo en las Facultades de Filosofía y Letras de las Universidades de Madrid y Barcelona, ésta última en régimen de autonomía: es el llamado "plan Morente", por el nombre del decano que lo aplicó en la Universidad Central ${ }^{16}$. En él se diversificaban las vías de entrada en la Facultad, se reducía el número de exámenes parciales o intermedios y se flexibilizaba tanto el régimen de convocatorias como el de libre elección de asignaturas y tutorías de profesores, con el bienintencionado objeto de fomentar "el interés personal

${ }^{13}$ José Deleito y Piñuela, La enseñanza de la Historia en la Universidad española... Sobre Deleito, destacado discípulo de Altamira e historiador modernista, vid. Pedro Torres Ruiz, Discursos sobre la historia. Lecciones de apertura de curso en la Universidad de Valencia... y "Política y ciencia de la historia en la Universidad de Valencia entre 1868 y 1939", en Carlos Forcadell e Ignacio Peiró, coord., Lecturas de la Historia. Nueve reflexiones sobre Historia de la Historiografía, Zaragoza, 2001, pp. 55-96.

${ }^{14}$ Antonio Molero Pintado y María del Mar del Pozo Andrés, ed., Un precedente histórico en la formación universitaria del profesorado español. Escuela de Estudios Superiores del Magisterio (1909-1932), Universidad de Alcalá de Henares, Madrid, 1989.

${ }^{15}$ Luis Palacios Bañuelos, Instituto-Escuela. Historia de una renovación educativa, Madrid, 1988.

${ }^{16}$ José María de Montiu de Nuix, Manuel García Morente. Vida y pensamiento, Madrid, 2010. Y el catálogo de la exposición La Facultad de Filosofía y Letras de Madrid en la Segunda República. Arquitectura y Universidad durante los años 30, Madrid, 2008. 
y la vocación" de cada alumno sin que estuviera "sujeto a constricciones de tipo escolar, rígido y encarrilado en normas inflexibles"17.

En realidad, los recursos y la financiación no pudieron crecer a un ritmo superior o al menos igual a la demanda de mayor calidad, a la difusión de los estudios universitarios de Historia y el aumento del número de profesionales, aunque hoy nos parezca tan pequeño: por eso, se daba la paradoja de que los defectos y los desequilibrios eran más visibles a medida que la situación también mejoraba. Porque, pese a sus limitaciones, la ley universitaria de 1900 y sus complementos en los años inmediatos fue fundamental y sus efectos permanecieron con pocos cambios estructurales hasta el último tercio del siglo $X^{18}$. En 1930, había Sección de Historia en siete universidades: Madrid, Barcelona, Valencia, Sevilla, Zaragoza, Valladolid y Santiago de Compostela.

La reforma de 1900 permitió la profundización y diversificación de las enseñanzas y ampliaciones sucesivas del número de cátedras, aunque hasta 1947 no comenzarían a institucionalizarse parcialmente las situaciones de los llamados antes auxiliares de cátedra y desde aquel año profesores adjuntos temporales. En 1936 había ya en torno a cien historiadores, la gran mayoría de ellos catedráticos universitarios, a los que se han de sumar sus auxiliares más destacados y algunos catedráticos de Instituto y archiveros facultativos, convergentes todos ellos en la profesionalidad ${ }^{19}$. Tal como escribía Deleito y Piñuela en 1930, se había pasado de una "historia política, lírica, cargada de

${ }^{17}$ Anuario de la Universidad de Madrid, 1932-1933, citado por Manuel Pérez Galán, La enseñanza en la Segunda República española, Madrid, 1975, p. 59.

${ }^{18}$ Algunas modificaciones tropezaron con especial resistencia, como ocurrió con las destinadas a dotar de personalidad jurídica autónoma a las universidades en lo relativo a estatutos, planes de estudios y gestión de recursos (R.D. de 21 mayo 1919, no aplicado, que tal vez da respuesta a algunas demandas expuestas por Deleito en 1918; R.D. 9 junio 1924. Decreto-ley 19 mayo 1928. Proyecto de Ley de Enseñanza Superior de marzo de 1933, que no venía acompañado por un plan de financiación anexo). La posibilidad de que algunos centros privados pudieran otorgar títulos, contemplada en D.L. 19 mayo 1928 sobre reforma de planes de estudios, levantó una tempestad de protestas en las Universidades públicas, incluso con cierre temporal de la Central, y hubo de retirarse. La Ley de Ordenación Universitaria de 29 julio 1943 mantuvo las Secciones de Historia y los elementos básicos de plan de estudios ya existentes. Sólo a partir de la Ley General de Educación de 1966 comenzaron los cambios significativos y rápidos en la organización de la enseñanza universitaria cuando, además, ya estaba creciendo muchísimo el número de estudiantes y otros elementos de demanda social. Vid. Historia de la Educación en España. III. De la Restauración a la Segunda República, Madrid, Ministerio de Educación y Ciencia, 1989.

${ }^{19}$ Gonzalo Pasamar Alzuría, "La profesión de historiador en la España franquista", en Carlos Forcadell e Ignacio Peiró, coord. Lecturas de la Historia. Nueve reflexiones sobre Historia de la Historiografía, Zaragoza, 2001, pp. 151-165. 
propaganda doctrinaria" propia del siglo XIX a otra "variada, de amplitud enciclopédica, serena y objetiva, caracterizada por el rigor de sus métodos de trabajo, su sentido crítico, su difusión en una gran masa de lectores" ${ }^{20}$.

La promoción de los estudios universitarios de Historia se manifestó también en la renovación y mejora de las obras de síntesis y metodología, tanto en calidad como en cantidad. En el segundo y tercer decenio del siglo XX se tradujeron grandes obras de Historia Universal y las publicaron editoriales con sede en Madrid o en Barcelona: la Historia del Mundo en la Edad Moderna de la Universidad de Cambridge (desde 1914, bajo la dirección de Eduardo Ibarra), la Historia General de E. Lavisse y A. Rambaud (desde 1908, por Vicente Blasco Ibáñez), la Historia Universal de Ch. Seignobos (desde 1915), la de Oncken (ed. original, 1879-1894; nueva edición española revisada, 1917-1922), muchos volúmenes de L'Évolution de l'Humanité, la gran empresa de síntesis que dirigía Henri Berr (Barcelona, editorial Cervantes) y, algo más adelante, la Historia Universal de W. Goetz (desde 1931, en versión de Manuel García Morente). Al mismo tiempo, se elaboraron obras originales, de extensión más reducida, que tuvieron gran difusión escolar: la Historia universal dirigida por E. Ibarra (1921-1929), la Historia Universal (novísimo estudio de la humanidad) del Instituto Editorial Gallach (Barcelona), o la Historia General de la Cultura de Manuel Ferrandis Torres (1934). Y, por primera vez, se planteó la síntesis de Historia de España como civilización o en relación con sus contextos generales: abrió esta nueva época Rafael Altamira con su Historia de España y de la civilización española (1900-1911), reelaborada luego en manuales más reducidos. Siguieron en la estela de Altamira otras síntesis como las de Rafael Ballester, Juan Ortega y Rubio, Eduardo Ibarra y Pío Zabala para Edad Moderna (España bajo los Austrias. España bajo los Borbones, $1927-$ -1929) y, en especial, la gran Historia de España y su influencia en la Historia Universal, de Antonio Ballesteros Beretta (primera edición, 1919-1941). Otra importante empresa de este género fue la Historia de España. Gran Historia General de los pueblos hispanos (Barcelona, 1934-1943, dirigida por Luis Pericot), y es preciso igualmente valorar la difusión que alcanzó, desde sus

${ }^{20}$ José Deleito y Piñuela, "Quelques données sur l'historiographie en Espagne de 1900 à 1930 du point de vue de la synthèse", Revue de Synthèse historique, tome L, 148-150 (1930), apéndice Bulletin du Centre International de Synthèse. Section de Synthèse historique, $\mathrm{n}^{\circ} 10$, pp. 29-49. Es de justicia señalar que este artículo de Deleito disimula, bajo su título modesto, una gran calidad de criterio y variedad de información bien seleccionada. 
primeras ediciones, la síntesis de Pedro Aguado Bleye (Manual de Historia de España, ediciones desde 1914 a 1956, con sucesivos aumentos de tamaño). Al término del periodo que ahora estudiamos, en 1934, comenzó a publicarse la gran Historia de España dirigida por Ramón Menéndez Pidal, una iniciativa editorial que tardó decenios en culminar, debido a su complejidad y magnitud crecientes así como a la variedad y gran número de sus colaboradores.

Al mismo tiempo, había surgido un conjunto de reflexiones e instrumentos útiles tanto para la metodología de la enseñanza como para la investigación histórica, consideradas como actividades enlazadas y complementarias. El libro de Rafael Altamira titulado La enseñanza de la Historia $\left(1891,2^{\mathrm{a}}\right.$ edición aumentada,1895) señaló ya los nuevos objetivos didácticos de una ciencia basada en el positivismo metodológico que tenía como horizonte la explicación de "principios" y "leyes" y el entendimiento de la "civilización" como conjunto. Las publicaciones de obras de metodología histórica se sucedieron desde la traducción de los libros de V. Langlois y Ch. Seignobos (Introducción a los estudios históricos, 1913) y E. Bernheim (Introducción al estudio de la historia, ed. original de 1898 ampliada en 1908; ed. española, 1937), y la elaboración de las obras de Altamira (Cuestiones modernas de Historia, 1904), Pío y Antonio Ballesteros (Cuestiones históricas (edades antigua y media), 1913) y Zacarías García Villada (Cómo se aprende a trabajar científicamente. Lecciones de metodología y crítica históricas, 1912). La traducción que hizo Luis García de Valdeavellano de la obra de W. Bauer (Introducción al estudio de la historia, $2^{\mathrm{a}}$ ed. 1927, ed. española, 1952), con amplios comentarios bibliográficos del traductor, vino a poner un punto final de máxima calidad a aquellas empresas de ilustración metodológica iniciadas medio siglo antes.

Así fue cómo la historiografía de síntesis del primer tercio del siglo XX marcó una época nueva, lejana ya de los ideales y objetivos historiográficos del XIX, con elementos interpretativos, metodológicos y expositivos cuyos aspectos básicos estaban llamados a permanecer hasta los años sesenta del siglo a pesar de los cambios de orientación ideológica impulsados por los poderes políticos ${ }^{21}$

Deleito señalaba en 1930, una vez más, que la labor de los profesores universitarios de Historia se dirigía mucho más a la formación de futuros profesores de enseñanza secundaria con una "cultura histórica general" que

${ }^{21}$ Gonzalo Pasamar e Ignacio Peiró, "La vulgarización de la historia y la consolidación de los valores burgueses en España: los manuales", en Historiografía y práctica social en España, Zaragoza, 1987, capítulo II. 
a la promoción de la investigación "tal como ocurre en otras universidades europeas". Sin embargo, había ya catedráticos, incluso pequeños grupos de investigadores, y tradiciones de especialización en algunas universidades. Así, en Zaragoza la historia de Aragón promovida sucesivamente por Eduardo Ibarra, Manuel Serrano y Sanz ${ }^{22}$ y Andrés Giménez Soler; en Barcelona, los cursos de historia y literatura catalana de Antonio Rubió y Lluch, los de derecho de Fernando Valls Taberner o los de prehistoria de Pedro Bosch Gimpera. En Valencia, donde destacaba la obra de José Deleito y Piñuela o algo más adelante la de Juan de Contreras, marqués de Lozoya, en el campo de la historia del arte. En Valladolid primaban los estudios de historia moderna, beneficiarios de la cercanía de los grandes archivos de Simancas y la Real Chancillería. En Granada los estudios árabes e islámicos, que contaron por algunos años con el Centro de Estudios Históricos de Granada y su Reino fundado por Mariano Gaspar y Remiro. En la Universidad de Sevilla la especialización en Historia del Arte se cultivaba en el seminario formado por Murillo Herrera y destacaba ya la investigación de Historia de América, contando con los fondos del Archivo General de Indias y la dotación de un Centro de Estudios Americanistas (José María Ots Capdequí; Diego Angulo en el ámbito de la historia del arte). El otro núcleo universitario de estudios americanistas radicaba en Madrid a partir de las iniciativas de Rafael de Altamira, continuadas por la dedicación a estos temas de Antonio Ballesteros Beretta, que establecería en 1934 el Seminario de Estudios Americanistas de la Universidad de Madrid ${ }^{23}$. En ella destacaba también desde los años veinte la figura del paleógrafo Agustín Millares Carlo que fue el gran promotor científico de esta especialidad, junto con Zacarías García Villada ${ }^{24}$.

\section{El Centro de Estudios Históricos}

Muchos de los resultados que no podían conseguirse plenamente en el ámbito de la organización universitaria, volcada siempre más hacia la enseñanza, se asignaron a una nueva institución de menores dimensiones pero

${ }^{22}$ José Antonio Gallego Gredilla, Serrano y Sanz en la historia (obra y vida de D. Manuel Serrano y Sanz), Guadalajara, 2006.

${ }^{23}$ Sobre la obra de Antonio Ballesteros Beretta: Antonio Rumeu de Armas, "Antonio Ballesteros Beretta", en Catedráticos en la Academia, Académicos en la Universidad... Ballesteros tuvo también una actividad muy importante como medievalista (Miguel Ángel Ladero Quesada, "Don Antonio Ballesteros Beretta, historiador de la Castilla medieval", en Homenaje y Memoria (I) (1999-2000), Madrid, Real Academia de la Historia, 2003, pp. 179-189).

${ }^{24}$ Luis García Iglesias, El P. Zacarías García Villada, académico, historiador y jesuita, Madrid, 1994. 
de mayor flexibilidad organizativa cuya sede estuvo en Madrid. Se trata de la Junta para Ampliación de Estudios e Investigaciones Científicas, fundada por R.D. 11 enero 1907 después de vencer algunas demoras y dificultades. La Junta (JAE en lo sucesivo) tendría como funciones el fomento de los trabajos de investigación, la protección a las instituciones de educación superior y secundaria, la concesión de bolsas de estudio para "pensionar" estancias de investigadores maduros o noveles, especialmente en universidades fuera de España, de tal modo que contribuyeran a abrirles camino en sus carreras profesionales, y el sostenimiento de las actividades de información y relación internacionales propias de aquellos fines. El primer presidente de la JAE fue Santiago Ramón y Cajal, y su eficaz secretario, hasta 1935, José Castillejo, un hombre de la Institución Libre de Enseñanza cuyos proyectos educativos y reformadores asumidos por la "izquierda liberal" burguesa estuvieron, desde luego, presentes a través de los directores y de muchos miembros de la JAE y los organismos nacidos en su seno o relacionados con ella: "transformación de la sociedad por medio de la educación y la ciencia, con el programa moral que ello entraña... sincronización de España con Europa" (J. Gómez Mendoza). Así sucedió que recibió tanto apoyos como recelos por motivos ideológicos y profesionales, incluso en medios universitarios que veían mal aquella escisión o ruptura de su ámbito de acción: La JAE dispuso habitualmente de entre un 10 y un 13 por 100 del presupuesto anual del Estado destinado a enseñanza universitaria, con máximos de 17,50, en 1927 y 19,60 en $1932^{25}$.

Entre las actividades de la JAE cuentan las casi dos mil "pensiones" dadas entre 1907 y 1936 para estancias de estudio en otros países, en especial Francia,

${ }^{25}$ Las relaciones políticas de la JAE fueron más fáciles con gobiernos del Partido Liberal durante la monarquía y con los republicanos de 1931-1933, pero se mantuvo siempre la continuidad de recursos y su limitación en un ambiente presupuestario general de escasez. El gobierno del general Franco suprimió la JAE en mayo de 1938 al mismo tiempo que creaba el Instituto de España y reorganizaba las Academias nacionales. El Consejo Superior de Investigaciones Científicas, fundado en noviembre de 1939, vino a tomar las funciones y recursos de la antigua JAE dentro del nuevo marco institucional y político. Bibliografía de referencia que utilizo principalmente: Josefina Gómez Mendoza, dir., La Junta para Ampliación de Estudios e Investigaciones Científicas y los académicos de la Historia, Madrid, 2008. M. A. Puig-Samper Mulero, ed.,, Tiempos de investigación.JAE-CISC, cien años de ciencia en España, Madrid, 2007. El laboratorio de España. La Junta para Ampliación de Estudios e Investigaciones Científicas. 1907-1939, Madrid, 2007 (catálogo de exposición). José María López Sánchez, Heterodoxos españoles. El Centro de Estudios Históricos, 1910-1936, Madrid, 2006. J. M. Sánchez Ron, ed., 1907-1987. La Junta para Ampliación de Estudios e Investigaciones Científicas, 80 años después, Madrid, 1988, 2 v.. Francisco Laporta, Javier Solana, Alfonso Ruiz Migual, Virgilio Zapatero, "Los orígenes culturales de la Junta para Ampliación de Estudios", Arbor (Madrid), 493 y 499 (1987), 17-87 y 9-137. 
Alemania, Bélgica y Suiza. En 1910 se estableció el Patronato de Estudiantes españoles fuera de España y el de estudiantes extranjeros en España, para regular mejor aquellas actividades, se fundó la Residencia de Estudiantes y, en 1915, la Residencia de Señoritas.

En lo que atañe a la investigación científica, La JAE agrupó sus laboratorios, seminarios y secciones en dos centros, el Instituto Nacional de Ciencias Físico-Naturales, presidido por Ramón y Cajal, y el Centro de Estudios Históricos (CEH), fundado por R.D. 18 marzo 1910, siendo ministro el conde de Romanones. Lo presidió desde 1915 Ramón Menéndez Pidal e intervinieron en su gestación, además de él, historiadores tan destacados como Rafael Altamira, Eduardo de Hinojosa, Elías Tormo, Manuel Gómez Moreno, Julián Ribera y Miguel Asín.

El decreto fundacional asignaba al CEH el "sagrado deber de descubrir nuestra propia historia patria en todas sus esferas", mediante investigaciones y edición de fuentes, excavaciones y encuestas, misiones científicas, trabajos "de laboratorio" en los que se "iniciara en los métodos de investigación a un corto número de alumnos", contando con el apoyo de la biblioteca especializada que también debería formarse.

Las Secciones del Centro se fueron organizando con un notable grado de plasticidad y diversa duración, según la disponibilidad de sus responsables, y con muy pocos medios materiales al comienzo, puesto que el CEH se albergó provisionalmente en locales del Archivo Histórico Nacional hasta 1920 en que pasó a ocupar un chalet alquilado en la calle Almagro y, desde 1929, tuvo su sede en el antiguo Palacio del Hielo, en la calle del duque de Medinaceli, donde permanecieron sus instituciones sucesoras hasta el año 2005.

Entre las Secciones efímeras hemos de contar la de Estudios sobre fray Luis de León, encomendada a la figura egregia de Marcelino Menéndez Pelayo, que murió en 1912. Tampoco duraron la Sección de filosofía contemporánea, a cargo de José Ortega y Gasset, cuyo influjo intelectual sobre los historiadores españoles del siglo XX fue muy grande, sobre todo por su reflexión filosófica y también por la acertada publicación de libros fundamentales en su editorial Revista de Occidente desde los años veinte del siglo ${ }^{26}$.

Tampoco arraigaron las Secciones de metodología de la historia, que habría regido Rafael Altamira y Crevea, ni la de Estudios de filología semítica, iniciada por Abraham S. Yahuda. En cambio, sí que lo hicieron los estudios de arte y arqueología promovidos por Elías Tormo y Manuel Gómez Moreno,

${ }^{26}$ Evelyne López Campillo, La "Revista de Occidente” y la formación de minorías (1923-1936), Madrid, 1972. 
los relativos a Instituciones sociales y políticas de León y Castilla, pese a la ruptura producida por la incapacitación de Eduardo de Hinojosa en 1914 y, en especial, los de Filología, dirigidos por Ramón Menéndez Pidal.

El CEH alcanzó su madurez en los años que transcurrieron entre 1923 y 1936. La Sección de Filología, la más importante y continua gracias a la excepcional calidad humana y profesional de su director ${ }^{27}$, emprendió investigaciones sobre orígenes e historia de la lengua y del medievo español (Menéndez Pidal, Orígenes del español, 1926. La España del Cid, 1929), textos literarios y cronísticos, atlas lingüístico de la península ibérica, fonética y otros, dirigidos por el mismo Menéndez Pidal con sus colaboradores, entre ellos Américo Castro, Tomás Navarro, Antonio García Solalinde, Federico de Onís, Samuel Gili Gaya, Amado Alonso, Homero Serís, Benito Sánchez Alonso, que editó en 1919 y de nuevo en 1927 sus Fuentes de la Historia Española e Hispanoamericana ${ }^{28}$, Juan de Mata Carriazo y Arroquia, editor en 1927 de la Crónica de los Reyes Católicos de Diego de Valera ${ }^{29}$, Dámaso Alonso, Rafael Lapesa... La Sección publicó desde 1914 la Revista de Filología Española. En los años 1932-1933 se desgajaron de ella nuevas secciones: Literatura española contemporánea

${ }^{27}$ La bibliografía sobre Menéndez Pidal es amplísima, en reconocimiento a su importancia capital para los estudios de Filología e Historia. Joaquín Pérez Villanueva, Ramón Menéndez. Pidal. Su vida y su tiempo, Madrid, 1991. J. I. Pérez Pascual, Ramón Menéndez Pidal. Ciencia y pasión, Valladolid, 1998. Ambos con noticia de las numerosas reseñas y estudios publicados con motivo de su fallecimiento en 1969 o en años posteriores. Rafael Lapesa, "Menéndez Pidal creador de escuela: el Centro de Estudios Históricos", en Alça la voz, pregonero. Homenaje a Don Ramón Menéndez Pidal, Madrid, 1979, pp. 43-79. José María Jover Zamora, "Menéndez Pidal y la historiografía española de su tiempo" en El legado cultural de España al siglo XXI, Madrid, 1992,pp. 43-103. Miguel Ángel Ladero Quesada: "Ramón Menéndez Pidal. Filología, Literatura e Historia”, en Catedráticos en la Academia, Académicos en la Universidad... (reed. En Lecturas sobre la España histórica, Madrid, 1998, pp. 287-316). María Luisa Vázquez de Parga, "Bibliografía de D. Ramón Menéndez Pidal”, Revista de Filología Española, 47 (1964), $8-127$.

${ }^{28}$ A tener en cuenta las publicaciones de Rafael Ballester y Castell, Bibliografía de la Historia de España. Catálogo metódico y cronológico de las fuentes y obras principales relativas a la Historia de España desde los orígenes hasta nuestros días, Barcelona, 1921. Su extensión era más reducida pero se refería a todos los ámbitos históricos, no sólo a la historia política. Ballester, como luego Sánchez Alonso, cultivó también la historia de la historiografía: Las fuentes narrativas de la Historia de España durante la Edad Media (417-1474) ... Durante la Edad Moderna (1474-1808), Palma de Mallorca, 1908; Valladolid, 1927. La gran Historia de la historiografía española. Ensayo de un examen de conjunto de Sánchez Alonso se publicaría en Madrid, 1941-1950.

29 Juan Luis Carriazo Rubio (ed.), Juan de Mata Carriazo y Arroquia. Perfiles de un centenario (1899-1999), Sevilla, Universidad, 2001. 
(Pedro Salinas) y Estudios clásicos (Vicente García de Diego; revista Emerita desde 1935) ${ }^{30}$.

La Sección de Estudios hispanoamericanos también nació a partir de la de Filología en 1933-1934, dirigida por Américo Castro. En ella comenzaron trabajos Antonio Rodríguez Moñino ${ }^{31}$, Manuel García Pelayo, Silvio Zavala, Manuel Ballesteros Gaibrois. Por entonces, estaba ya consolidado el Centro de Estudios Americanistas o de Historia de América, en la Universidad de Sevilla, cuyo director fue José María Ots Capdequí entre 1932 y 1936.

La Sección de Historia del Derecho y de las instituciones se rehizo gracias a antiguos colaboradores y discípulos de Hinojosa (m. 1919): Galo Sánchez ${ }^{32}$, Rafael de Ureña y Smenjaud ${ }^{33}$, Laureano Díez-Canseco, José María Ramos Loscertales, Claudio Sánchez-Albornoz, Manuel Torres López; con menor

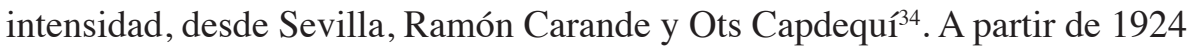
publicó el Anuario de Historia del Derecho Español. Sánchez-Albornoz, sin duda la figura central ${ }^{35}$, dirigió desde 1928 un Seminario de historia de las

${ }^{30}$ Además de la bibliografía general citada, José A. Pascual, "La historia de la lengua en la Junta para Ampliación de Estudios", La Junta...(2008), pp. 145-174.

${ }^{31}$ Rafael Rodríguez-Moñino Soriano, La vida y la obra del bibliófilo y bibliógrafo extremeño D. Antonio Rodríguez-Moñino, Mérida, 2000.

32 Además de su amplia obra de investigación, recordemos su traducción de Ernest Mayer, Historia de las instituciones sociales y políticas de España y Portugal durante los siglos $V$ al XIV, Madrid, 1925.

${ }^{33}$ Rosa Ureña Francés, Rafael de Ureña y Smenjaud. Una biografía intelectual, Oviedo, 2002

${ }^{34}$ La singular personalidad e importante obra histórica de don Ramón Carande, en Rocío Yñiguez Ovando, Ramón Carande, un siglo de vida, Madrid, 2002. Bernardo Víctor Carande, Ramón Carande, biografía ilustrada, Sevilla, 2003. El mismo don Ramón publicó notables perfiles de algunos de sus contemporáneos historiadores: Galería de raros y Galería de amigos, Madrid, 1989. También, Antonio Miguel Bernal, "Don Ramón Carande: la proyección internacional de la historiografía española en el siglo XX", en Jerónimo Zurita. Revista de Historia, 73 (1998), 225-242. Gonzalo Anes, "Los académicos don Ramón Carande, don Luis García de Valdeavellano, don José Antonio Rubio y don Ángel Ferrari en la Junta de Ampliación de Estudios", en Josefina Gómez Mendoza (dir.), La Junta para ampliación..., Madrid, 2008, pp. 49-114.

${ }^{35}$ Luis García de Valdeavellano, "El tema y los temas de Sánchez-Albornoz", Revista de Occidente, 50 (1985). José Manuel Pérez-Prendes, "Semblanza y obra de don Claudio Sánchez-Albornoz", En la España Medieval (Madrid), 8 (1986), 19-52. Los artículos de Fernando J. Devoto, Nilda Guglielmi y María E. González de Fauve contenidos en el Homenaje a Claudio Sánchez-Albornoz. Cuadernos de Historia de España (Buenos Aires), LXXVII (2001-2002). Sánchez-Albornoz a debate. Homenaje de la Universidad de Valladolid, Valladolid, 1993. Eloy Benito Ruano, "Claudio Sánchez-Albornoz y el medievalismo español”, en Catedráticos en la Academia, Académicos en la Universidad. Miguel Ángel Ladero Quesada, “Es todavía España un "enigma histórico"?. Releyendo a Sánchez-Albornoz”, en Lecturas sobre la España 
instituciones medievales españolas transformado en enero de 1932 en Instituto de Estudios Medievales, con subsecciones de Instituciones, Fueros, Diplomas y Crónicas, cuyo objetivo principal sería la publicación de los Monumenta Hispaniae Historica, aunque también atendió a la edición de cartularios y otras obras, como se venía haciendo desde la década anterior ${ }^{36}$. Allí comenzaron su formación como historiadores Luis García de Valdeavellano, catedrático de Historia del Derecho ya en $1933^{37}$, José María Lacarra de Miguel ${ }^{38}$, Luis Vázquez de Parga, Alfonso García Gallo, Ángel Ferrari Núñez ya en 1936, Pedro Longás Bartibás, y archiveros como Gerardo Núñez, Consuelo Gutiérrez del Arroyo, Ana Pardo, María Brey, Carmem Pescador o Pilar Loscertales, entre otros.

Las Secciones de Arqueología y Arte medieval español y Arte escultórico y pictórico de España en la Edad Media y el Renacimiento, dirigidas por Manuel Gómez Moreno y Elías Tormo y Monzó respectivamente, colaboraron en la edición, desde 1925, del Archivo Español de Arte y Arqueología. Por su parte, Gómez Moreno había promovido desde comienzos de siglo la abrumadora y discontinua tarea de publicar algunos de los volúmenes del Catálogo Monumental de España, por provincias, en una labor que prolongaba y ampliaba la de las Comisiones Provinciales de Monumentos, que supervisaban la Academia de la Historia y la de Bellas Artes de San Fernando desde 1847. Aquí es preciso recordar también la obra precursora de Vicente Lampérez y Romea (m. 1923), gran historiador de la arquitectura española. Años después, en 1931, el CEH estableció en su sede un "Fichero artístico nacional" acumulativo, una de cuyas finalidades fue sustituir al antiguo Diccionario de Cean Bermúdez, publicado en 1800 .

Junto a los fundadores de ambas Secciones comenzaron a destacar otros estudiosos como Francisco Javier Sánchez Cantón, Leopoldo Torres Balbás en Granada, Ricardo de Orueta, Diego Angulo, Enrique Lafuente Ferrari, Juan de Mata Carriazo, Jesús Dominguez Bordona, Cayetano Mergelina, Emilio Camps

histórica, Madrid, 1998, pp. 317-341. Sonsoles Cabeza Sánchez-Albornoz, Semblanza histórico- política de Claudio Sánchez-Albornoz, Madrid, 1993.

${ }^{36}$ Un buen ejemplo de libro útil para la iniciación en el manejo de fuentes fue el de Claudio Sánchez-Albornoz y Aurelio Viñas, Lecturas de historia de España, Madrid, 1929, manejado por generaciones de estudiantes universitarios.

${ }^{37}$ Miguel Ángel Ladero Quesada, "Don Luis García de Valdeavellano y Arcimis", Revista de Historia Económica, III/2 (1985), 299-306. José Manuel Pérez-Prendes, II, "Luis García de Valdeavellano", Jerónimo Zurita. Revista de Historia, 73 (1998), 259-282. Gonzalo Anes, "Luis García de Valdeavellano", en Catedráticos en la Academia, Académicos en la Universidad.

38 José Ángel Sesma Muñoz, "El discreto magisterio de don José María Lacarra", Jerónimo Zurita. Revista de Historia, 73 (1998), 69-88. 
Cazorla, Luis Siret, Joaquín de Navascués, Antonio García y Bellido o Julio Martínez Santa Olalla, Juan Cabré en materias etnográficas ${ }^{39}$, y Manuel de Terán en sus comienzos puesto que en el CEH no hubo Sección de Geografía aunque la JAE pensionara en el extranjero a geógrafos como Juan Dantín Cereceda, entre 1910 y 1913, Luis Solé Sabarís y el mismo Terán en 1933.

Por otra parte, es cierto que la arqueología moderna española se desarrolló preferentemente en ámbitos exteriores al $\mathrm{CEH}$, tanto en Madrid como en Barcelona. Así, en el Museo Arqueológico Nacional, por obra de su director, José Ramón Mélida, catedrático además de la Universidad de Madrid, donde lo fue también desde 1922 el sacerdote y geólogo alemán Hugo Obermaier, una figura clave junto con Breuil y Teilhard de Chardin en la "reconciliación" de la Iglesia Católica con la prehistoria. Con Mélida, con Obermaier o con ambos estudiaron Martín Almagro Basch, Antonio García Bellido y Julio Martínez Santa Olalla. Y en Barcelona destacó la obra fundadora de Pedro Bosch Gimpera (desde su Prehistoria de Cataluña, 1919), continuada por su discípulo Luis Pericot. Casi todos ellos, en uno u otro momento, dispusieron de pensiones para estancias en el extranjero concedidas por la $\mathrm{JAE}^{40}$.

El arabismo, representado en un primer momento por Julián Ribera y Miguel Asín Palacios, se desgajó del CEH a partir de 1917 y siguió su propio camino en las cátedras de las universidades de Madrid, Zaragoza y Granada. En enero de 1932, el gobierno estableció las Escuelas de Estudios Árabes de Madrid y Granada, que editaron la revista Al Andalus desde 1934, bajo la dirección de Asín y de su discípulo Emilio García Gómez ${ }^{41}$. Otro de ellos, Ángel González Palencia, había publicado en 1926-1930 la gran colección de

${ }^{39}$ Los estudios de etnografía y folklore siguieron derroteros propios, al margen de los vínculos que algunos de sus autores tuvieron en ocasiones con el CEH. Destacan en aquellos decenios las figuras de Francisco Rodríguez Marín, historiador de la literatura y director de la Biblioteca Nacional, Manuel Antón y Ferrándiz, algo anterior, Telesforo de Aranzadi y Unamuno y Luis de Hoyos Sainz. Aranzadi y Hoyos fueron autores de las primeras síntesis, a partir d la antropología física (Un avance a la antropñología de España, 1892; Antropología de España, 1915; Etnografía. Sus bases, métodos y aplicaciones a España, 1917).

${ }^{40}$ José Manuel Pita Andrade y Alfonso E. Pérez Sánchez, "Los académicos de la historia y la Junta: Historia del Arte y JAEIC", en La Junta..., pp. 175-205. Martín Almagro Gorbea, "La Real Academia de la Historia y el Centro de Estudios Históricos: la arqueología", en Catedráticos en la Academia, Académicos en la Universidad, Madrid, Universidad Complutense-Fundación Central Hispano, 1993, pp. 115-144.

${ }^{41}$ Joaquín Vallvé Bermejo, "El arabismo en la Universidad Complutense en el siglo XX", en Catedráticos en la Academia, Académicos en la Universidad, pp. 97-132. Sobre las grandes figuras del siglo XIX (Pascual de Gayangos, Francisco Codera y Zaidín), vid. también Manuel Manzanares de Cirre, Arabistas españoles del siglo XIX, Madrid, 1972. J. T. Monroe, Islam and the Arabs in Spanish scholarship (Sixteenth Century to the present), Leiden, 1970. Fernando de 
manuscritos mozárabes de la catedral de Toledo, mientras Antonio Prieto y Vives se especializaba en materia numismática.

La dirección de las Secciones del CEH estuvo -ya lo he indicado- en manos de catedráticos de Universidad, generalmente la de Madrid, que seguían trabajando también en ella, y elegían a sus colaboradores para llevar a cabo con ellos seminarios frecuentes en torno a los temas de investigación y edición en curso, además de dirigir trabajos de becarios y pensionados, cuando los había, y de organizar viajes de estudio y excursiones complementarias ${ }^{42}$. El CEH fue sobre todo, por lo tanto, un ámbito de investigación con autonomía administrativa y financiera, aunque modesta, movido por el trabajo de pequeños grupos, organizado de manera más flexible que las Facultades universitarias. En él crecieron las formas modernas de investigación científico-humanística en España y trabajaron muchos de sus primeros grandes maestros: este hecho fundamental fue irreversible, tuvo continuidad profesional y, al cabo, siguió aumentando en medio de las rupturas y cambios de orientación político-ideológica promovidos desde el poder a partir de $1939^{43}$.

El CEH, utilizando recursos de la JAE, puso en pie también una red de relaciones exteriores que amplió duraderamente los horizontes de filólogos e historiadores españoles. Después de los viajes por la América hispana de Rafael Altamira en 1909-1910 y Adolfo González Posada al año siguiente,

Ágreda Burillo, "Don Ángel González Palencia. 1889-1949: apuntes biográficos”, Anaquel de Estudios Árabes (Madrid), 9 (1998), 215-238.

${ }^{42}$ Ha alcanzado caracteres casi míticos la organizada por diversas instituciones en 1933: Francisco Gracia Alonso, El sueño de una generación. Crucero Universitario por el Mediterráneo (Verano de 1933), Madrid, 1995.

${ }^{43}$ Noticias útiles sobre actividad profesional en Gonzalo Pasamar Alzuría, Historiografía e ideología en la postguerra española: la ruptura de la tradición liberal, Zaragoza, 1991, y "La profesión de historiador en la España franquista", en Carlos Forcadell e Ignacio Peiró, coord.., Lecturas de la Historia. Nueve reflexiones sobre Historia de la Historiografía, Zaragoza, 2001, pp.151-165. También, Juan José Carreras Ares y M. A. Ruiz Carnicer, coord., La universidad española bajo el régimen de Franco. 1939-1975, Zaragoza, 1991. Gregorio Morán, El maestro en el erial: Ortega y Gasset y la cultura del franquismo, Barcelona, 1998. Carolina Rodríguez López, La universidad de Madrid en el primer franquismo: ruptura y continuidad (1939-1951), Madrid, 2002. J. M. Hernández Bueno, "Continuidad y ruptura en la universidad española del siglo XX”, en Ángel Vaca Lorenzo, ed., Educación y transmisión de conocimientos en la historia, Salamanca, 2002. Jaume Claret Miranda, El atroz desmoche: la destrucción de la Universidad española por el franquismo, 1936-1945, Barcelona, 2006. Las propuestas de interpretación y valoración de aquellos años se muestran generalmente desde el mismo título de algunas de estas publicaciones. 
Menéndez Pidal inauguró la Institución Cultural Española de Buenos Aires en 1914, iniciando un acercamiento cultural que continuaría con la organización del Instituto de Filología de la Universidad de Buenos Aires y los intercambios de profesores, coordinados por Américo Castro. Por su parte, Federico de Onís promovió el Instituto de las Españas en la Universidad de Columbia (Nueva York) desde 1918 y estableció la Revista de Estudios Hispánicos de la de Puerto Rico en 1928. Además, Menéndez Pidal dirigió desde 1912 hasta 1934 los cursos de verano de lengua, literatura, historia y arte para extranjeros que organizaba la JAE, a los que acudieron cientos de graduados norteamericanos, británicos, alemanes y, en menor número, franceses, y la Sección correspondiente del CEH organizó gran parte del intercambio de los llamados "repetidores de español" en universidades extranjeras con otros procedentes de sus respectivos países, Francia en especial gracias a la colaboración del Institut Français en Madrid.

Del CEH dependió la Escuela Española de Historia y Arqueología en Roma, fundada por R.D. de 6 de junio de 1910, donde fue clave la figura de su primer secretario, José Pijoan, gran promotor más tarde de obras de síntesis sobre historia universal e historia del arte, y trabajó algunos años el benedictino Luciano Serrano, pero la Escuela se eclipsó desde 1915 durante las dificultades de la Gran Guerra, estuvo cerrada desde 1921 y no reanudó sus actividades, en el marco del Consejo Superior de Investigaciones Científicas, hasta $1947^{44}$.

Por último, la Universidad Internacional de Verano de Santander nació en 1932, por iniciativa del profesor Fernando de los Ríos, ministro entonces de Instrucción Pública. No tuvo vinculación institucional con la JAE pero ambas compartieron recursos humanos y la nueva Universidad vino a sumarse eficazmente al conjunto de medios de relación cultural exterior y difusión de investigaciones.

\section{La Academia de la Historia}

Las novedades que acabo de describir fueron desarrollándose y surtiendo efecto paulatinamente. Por una parte, escribe Peiró, "las Universidades dejaron de ser establecimientos subordinados a las Academias para convertirse en los auténticos y prácticamente exclusivos centros rectores de la cultura y de la conciencia histórica española" puesto que también fueron catedráticos

${ }^{44}$ Manuel Espadas Burgos, La Escuela Española de Historia y Arqueología en Roma: un Guadiana junto al Tíber, Madrid-Roma, 2000. 
universitarios quienes dirigieron el $\mathrm{CEH}^{45}$. Por otra parte, se acentuó la profesionalización y especialización de los historiadores en el seno de las nuevas tendencias, donde resultaba anacrónica la figura del "historiador académico, erudito y diletante, característica de la primera etapa de la Restauración".

Es preciso, con todo, mantener la sensibilidad hacia los matices y las transiciones junto con la afirmación de los contrastes y las novedades cuando se observa la situación efectiva y las tendencias que se manifiestan durante el primer tercio del siglo XX. Así, los miembros del Cuerpo Facultativo de Archiveros y Bibliotecarios tuvieron un papel muy importante en el desarrollo historiográfico de aquella época, a partir de la crítica, descripción y edición de fuentes y estudios anejos, sin necesidad de romper con los ideales eruditos del positivismo, y algunos de sus miembros más destacados continuaron sus carreras profesionales como catedráticos de Universidad en la primera mitad del siglo, en especial en el ámbito del medievalismo ${ }^{46}$.

La Academia de la Historia, por su parte, mantuvo su papel como centro de referencia y prestigio, "siendo, en última instancia, el organismo tutelar de la historiografía española". Deleito y Piñuela la describía en 1930 como la "élite de escritores cuyo renombre se ha consagrado mediante largos años de investigaciones históricas" y ponderaba su función de tutela e informe, de publicación y premio de obras destacadas. Todo ello en circunstancias distintas, donde ya no era única ni imprescindible su iniciativa en la "organización de los trabajos históricos", como de hecho lo había sido antaño porque otras instituciones absorbían casi todos los recursos públicos destinados a tales fines. Pero esta pérdida de peso relativo se compensaba con una ganancia evidente: el cuerpo de académicos numerarios se fue profesionalizando y la Academia pudo mantenerse así como punto de referencia permanente y efectivo de la historiografía española, y como "símbolo de prestigio" para la profesión de historiador ante el conjunto de la sociedad, cosa que tal vez no habría podido ocurrir, en las nuevas circunstancias, de haber seguido estando formada la corporación por "aquel grupo de notables y eclesiásticos, funcionarios y burgueses ilustrados, aficionados a los estudios de historia, que, hasta entonces,

${ }^{45}$ La palabra "subordinación”, utilizada por Peiró (Los guardianes de la historia...) debe entenderse, a mi parecer, en el terreno intelectual y de honor pero no en el jerárquico, institucional y administrativo ya que las Universidades nunca dependieron en estos aspectos de las Academias.

${ }^{46}$ Agustín Ruiz Cabriada, Bio-bibliografía del Cuerpo Facultativo de Archiveros, Bibliotecarios y Arqueólogos, 1858-1958, Madrid, 1958. Entre los continuadores de Menéndez Pelayo es indispensable recordar los nombres de Eduardo Bonilla San Martín en el ámbito de la historia de la filosofía, Francisco Rodríguez Marín, historiador de la literatura popular y cervantista, y Miguel Artigas, organizador de la Biblioteca Menéndez Pelayo de Santander. 
componían el núcleo principal" (Peiró), en gran medida, justo es también decirlo, porque había muy pocos historiadores profesionales.

El hecho es que de los 136 académicos numerarios nombrados entre 1845 y 1915, sólo nueve eran catedráticos y catorce archiveros, mientras que entre 1915 y 1939, de cuarenta y dos nombramientos, dieciséis recayeron en catedráticos, cuatro en archiveros y otros tres eran historiadores o filólogos de profesión. Y, además, se contaban entre los miembros más notables de su respectiva especialidad: se ha señalado, por ejemplo, que casi todos los directores de secciones del Centro de Estudios Históricos hasta 1936 fueron también académicos. El número e importancia de los que no eran historiadores profesionales de alguna especialidad -incluyendo historia del arte, genealogía y heráldica, así como filólogos con obra de historiador- siguió siendo notable aunque en paulatina disminución.

\section{Instituciones regionales y provinciales}

Una realidad importante, en auge desde finales del siglo XIX, fue la incorporación activa de interpretaciones regionalistas a la concepción de la historia nacional española. Sobre bases anteriores, que a menudo permanecían en el tradicional plano de la historia local, buen número de centros culturales de ámbito regional o provincial aumentaron su actividad o, en otros casos, nacieron en la época que ahora estudiamos. En todos ellos tuvo importancia el cultivo de la Historia, a veces por obra de eruditos locales, otras con participación de historiadores universitarios, archiveros y otros profesionales de corte metodológico más moderno aunque siempre dentro del común estilo positivista de la época, y contaron generalmente con revistas y publicaciones. Me limitaré a enumerar algunos historiadores e instituciones principales:

- Galicia. Manuel Murguía. López Ferreiro. - Real Academia Gallega.

- Asturias. Ciriaco Miguel Vigil. Nicolás Tenorio Cerero.

- Santander. Instalación de la Biblioteca Menéndez y Pelayo en 1919.

- País Vasco. Se escriben o difunden síntesis de valor muy desigual, como son las de Sagarminaga, Artiñano, Labayru, Iturriza y Guiard para Vizcaya, las de Soraluce y Gorosábel sobre Guipúzcoa, o las de Carmelo de Echegaray y Juan Antonio Zamacola sobre las Vascongadas, en general. - Sociedad de Estudios Vascos, con sede en San Sebastián.

- Toledo. Real Academia de Bellas Letras y Ciencias Históricas.

- Badajoz. Centro de Estudios Extremeños.

- Córdoba. Academia de Ciencias, Bellas Letras y Nobles Artes. 
- Sevilla. Sociedad Archivo Hispalense. - Academia de Letras y Artes. Investigaciones de Nicolás Tenorio Cerero, Claudio Sanz Arizmendi, Antonio Ballesteros Beretta, Manuel Muñoz Torrado.

- Cádiz. Real Academia Hispano-americana

- Granada. Centro de Estudios Históricos de Granada y su reino

- Mallorca. Sociedad Arqueológica Luliana

- Valencia. Lo Rat-penat. - Centro de cultura valenciana. - Archivo de arte valenciano

- Castellón. Sociedad Castellonense de Cultura

- Tenerife. Instituto de Estudios Canarios. - Elías Serra Ráfols, José Peraza de Ayala.

También en Madrid se formó un núcleo apreciable de historia local en torno a la Revista de la Biblioteca, Archivo y Museo del Ayuntamiento desde 1924 (A. Millares Carlo). El fenómeno se observa igualmente en otras capitales regionales o provinciales pero de manera incipiente o con menor impulso. En algunos casos estuvo más vinculado a la Universidad, como sucedió en Zaragoza (Ibarra, Sangorrín, Salarrullana de Dios, Giménez Soler...) y Oviedo. En otros no alcanzó la continuidad e intensidad precisas, especialmente en tierras de León y las dos Castillas, incluso en Valladolid, donde tuvieron mayor continuidad algunas iniciativas (Revista Histórica. - Sociedad castellana de excursiones. - Sociedad de estudios históricos castellanos).

Por el contrario, las circunstancias culturales y políticas de Cataluña favorecieron el rápido impulso y madurez de instituciones propias donde el cultivo de la investigación histórica tuvo mucha importancia: así sucedió en la Real Academia de Buenas Letras de Barcelona y, especialmente, en el Institut d'Estudis Catalans, fundado en 1907, con una activa Sección históricoarqueológica. Otras instituciones culturales, como la Fundación Bernat Metge, aportaban también medios. En aquellas circunstancias, contando con la presencia de la Universidad y el recurso del Archivo de la Corona de Aragón, maduraron generaciones de historiadores, medievalistas muchos de ellos, especialistas otros en historia cultural, del arte y de las letras catalanas, cuya obra se añade a la de los que ya he mencionado páginas atrás: Francisco Carreras y Candi, Joaquín Miret y Sans, Antonio Rovira y Virgili, Luis Nicolau d'Olwer, Fernando Valls Taberner, Ferran Soldevila, ... ${ }^{47}$. El comienzo de los Congresos de Historia de

${ }^{47}$ L'Institut d'Estudis Catalans, 90 anys (1907-1997), Barcelona, 1997 (catálogo de exposición). Albert Balcells, Santiago Izquierdo, Enric Pujol, Història de l'Institut d'Estudis Catalans, Barcelona, 2007, 2 v.. Algunas personalidades: Albert Balcells, Antoni Rubió i Lluch, 
la Corona de Aragón debe relacionarse principalmente con este florecimiento historiográfico ${ }^{48}$.

\section{Los hispanistas}

La maduración del hispanismo en el seno de la cultura superior francesa es también una realidad cuya importancia debe tenerse en cuenta para entender mejor la evolución de los estudios históricos y literarios en España desde aquellos decenios, así como los estímulos que recibían. Su fundador fue Alfred Morel-Fatio, cuyos contactos con nuestro país comenzaron en 1875-1876 y se plasmaron en una primera valoración sobre las características y limitaciones de su historiografía ${ }^{49}$. Morel-Fatio y sus discípulos hicieron arraigar los estudios de lengua y cultura hispánicas en Toulouse (Ernest Mérimée), Burdeos (Georges Cirot, publicación del Bulletin Hispanique desde 1899), y París, donde, además de Morel-Fatio en la École Pratique des Hautes Études, destacó la figura de Louis Barrau-Dihigo. Caso aparte es la personalidad y la obra de Raymond Foulché-Delbosc, que fundó en 1894 y mantuvo durante cuarenta años la Revue Hispanique, publicación fundamental en muchos aspectos, dotada de una amplia perspectiva temática y territorial. Entre los historiadores especializados en el pasado español destacaban ya los nombres de Prosper Boissonnade ${ }^{50}$, Georges Desdevises du Dezert ${ }^{51}$ y Joseph Calmette.

historiador i primer president de l'Institut d'Estudis Catalans, Barcelona, 2001. Rosa Montoriol, Ferran Soldevila. 1894-1971. Una aproximación bio-bbliográfica, Barcelona, 1994. Francesc Vilanova, Ramon d'Abadal: entre la història i la política, Lleida, 1996. Carles Millares, Lluis Nicolau d'Olwer, Barcelona, 2000. Eulalia Duran, Agustí Duran i Sampere, Barcelona, 2000. María Teresa Ferrer i Mallol, Joaquim Miret i Sans, Barcelona, 2003. José María Mas Solench, Fernando Valls Taberner. Una vida entre la historia y la política, Barcelona, 2004. Sobre la elaboración de un modelo explicativo propio de la historia española, es interesante leer el discurso de Pedro Bosch Gimpera en la inauguración del curso 1937-1938 de la Universidad de Valencia, titulado España (vid. Pedro Ruiz Torres, "Política y ciencia en la historia...", cit. en la nota 13.

${ }^{48}$ Barcelona, 1908, Huesca, 1920, Valencia, 1923. No hubo todavía la continuidad que alcanzaron desde su renacimiento, más que reanudación, en 1952.

${ }^{49}$ Antonio Niño, Cultura y diplomacia. Los hispanistas franceses y España. 1875-1931, Madrid, 1988. La valoración de Morel-Fatio sobre la obra de los historiadores españoles del momento en Revue Historique, III (1877), 381-410 (resumen en Niño, Cultura..., pp. 48-64. Para épocas más recientes, Benoit Pellistrandi ed., La historiografía francesa del siglo XX y su acogida en España, Madrid, 2002.

${ }^{50}$ Entre sus obras generales de crítica histórica, Les études relatives à l'histoire économique de l'Espagne et ses résultats, Paris, 1913.

${ }^{51}$ Vid. su "Bibliografía de la historia de España. Edades antigua y media", en Revista de Aragón, 1905. 
El establecimiento de la École des Hautes Études Hispaniques de Madrid en 1909, por iniciativa de la Universidad de Burdeos, y la del Institut Français en 1913 vinieron a consolidar el respaldo permanente de unas relaciones que se consolidaron en los años siguientes mediante el envío de misiones culturales y la formación de comités permanentes. Intervinieron activamente en ellos por parte española historiadores de primera importancia como Rafael de Altamira y Ramón Menéndez-Pidal, o grandes promotores culturales, como Jacobo Fitz-James Stuart Falcó, duque de Alba, que fue numerario de la Real Academia de la Historia desde 1919. El establecimiento de centros de residencia y estudio de investigadores fue otra consecuencia duradera de aquella relación (inauguraciones de la Casa de Velázquez en Madrid, 1928, y del Colegio de España en París, 1935).

Algunas figuras aparecen al margen de las anteriores iniciativas, como la de J. Regné, recopilador de documentos sobre los judíos de Aragón, o la del insigne E. Lévi-Provençal, historiador de Al Andalus, o la del belga Ch. Verlinden, joven historiador en los años veinte de la esclavitud y de la primera expansión atlántica. Del mismo modo, los investigadores de otros países actuaban también solos o con respaldos institucionales menos explícitos y continuos, como sucedió con los norteamericanos E. J. Hamilton, J. Klein o R. B. Merriman, aunque en Nueva York se constituyó la Hispanic Society y su fundador, Archer M. Huntington, patrocinó diversas empresas, entre ellas la Revue Hispanique de Foulché-Delbosc.

El interés de historiadores del ámbito alemán dio lugar a investigaciones sustanciales sobre diversos aspectos y épocas. Recordemos, al menos, la influencia que tuvieron las investigaciones de A. Schulten sobre la Hispania pre-romana y romana, las obras de P. F. Kehr, H. Finke, J. Vincke y P.E. Schramm, especialmente para el ámbito de la documentación pontificia y la antigua Corona de Aragón; las de P. Rassow y R. Konetzke. Y, en fin, la gran recopilación documental sobre los judíos medievales de Castilla, llevada a cabo por F. [Yitzak] Baer.

\section{Colofón}

Sería objeto de trabajos mucho más extensos que éste estudiar con detalle los temas y resultados de la investigación y la síntesis, los métodos y los objetivos de la historiografía de aquellos decenios, y los diversos horizontes interpretativos del pasado hispánico que se consolidaron entonces, con difusión social y ámbito de aceptación muy desiguales. Aquí sólo se ha dado un primer paso al mencionar los nombres de muchos historiadores principales en los marcos institucionales 
donde habitualmente trabajaron y, en algunos casos, aludir a los ámbitos y épocas de la historia por los que se interesaron principalmente. El mero hecho de evocarlos da idea de la importancia fundadora que tuvo aquella época de primera madurez y nos permite valorar con mayor profundidad temporal los cambios que han ido experimentando tanto las finalidades, métodos y dimensión de las investigaciones como las propuestas de interpretación de la historia española, su uso político y social, y la posible confluencia de sus aportaciones ${ }^{52}$.

Recebido em/Text submitted on: 17/02/2011

Aceite em/Approved on: 16/05/2011

${ }^{52}$ He facilitado referencias bibliográficas sobre algunos historiadores en varias notas de este trabajo pero no he pretendido dar noticia de todo puesto no era el objeto principal de esta breve síntesis y, además, la información está dispersa a menudo en notas necrológicas, bio-bibliografías colectivas, prólogos, breves artículos de prensa periódica y otras publicaciones menores. Es conveniente consultar los datos que publican Ignacio Peiró Martín y Gonzalo Pasamar Alzuria, Diccionario Akal de Historiadores españoles contemporáneos (1840-1980), Madrid, 2002, 699 p. (primer trabajo de conjunto sobre la cuestión abundantemente documentado). También, José María Jover Zamora, Historiadores españoles de nuestro siglo, Madrid, 1999. Hay muchos artículos sobre historiadores en el Diccionario Biográfico Español que publica la Real Academia de la Historia desde 2010. 